\title{
ERRATUM
}

Advs Exp Med Biol - Advances in Microbiology, Infectious Diseases and Public Health DOI 10.1007/5584_2017_21

(C) Springer International Publishing Switzerland 2017

\section{Microbiological Diagnosis of Implant- Related Infections: Scientific Evidence and Cost/Benefit Analysis of Routine Antibiofilm Processing}

\author{
Lorenzo Drago and Elena De Vecchi
}

The original chapter was published with an incorrect subseries name Adv Exp Med Biol - Advances in Internal Medicine which is now corrected to Adv Exp Med Biol - Advances in Microbiology, Infectious Diseases and Public Health. 